\title{
American Medical Informatics Review for 2011
}

\author{
Ralph Grams
}

Published online: 18 February 2012

(C) Springer Science+Business Media, LLC 2012

With the beginning of a new year, we need to review and reflect on what has happened in the last 12 months and see if this gives us any insight for the future. Are we moving forward or going backward? Is medicine getting more productive or is it losing ground? Are the patients better off or getting poorer care and services? Are the doctors and staff feeling better about their jobs or are they discouraged? Is the bureaucracy getting more restrictive or providing appropriate protections for all parties? Will the IT revolution taking place in hospitals and clinics be a positive or negative influence on the future of American healthcare delivery?

These are important questions to proper and the only answers will come by looking at the published records for the last year.

\section{The physician and the patient-2011}

The physician is definitely under stress this past year with the reduction in payments and the lack of coverage for requested services. New doctors are electing to select specialties and practices that offer 40 hours or less a week with no call and no weekend services required [1]. With increased financial pressures, physicians in private practice are going broke at an alarming rate. Many are going to their banks to make payroll. This is a direct result of decreased payments for services and delayed payments from insurance providers [2]. Because of the constant demand from insurance companies for more documentation, the physician's

R. Grams $(\bowtie)$

Department of Pathology, College of Medicine,

University of Florida,

Gainesville, FL 32610, USA

e-mail: kqinc@aol.com time is being spent justifying claims to insurance carriers with no financial reward for this effort. Some physicians have started charging an annual fee for these services that is upsetting to patients and their families [3]. These issues are placing a huge stress on the private sector of medical care and hitting those who are least able to defend their position and hire legal aid to assist in their defense. Medicare cuts are on the table every year and there is no place for physicians to go but close their practice. This is going to create a huge demand on existing providers and make our healthcare system inaccessible for the average patient and especially for our seniors. When you see the lack of interest in young physicians to take on this challenge and the retirement of our senior specialists in medicine, this can not bode well for our future healthcare delivery system.

Doctors can no longer look to their leaders for good advice or comfort. Dr. Berwick was given the role of CMS (Centers for Medicare and Medicaid Services) director by President Obama without Congressional approval. In his recent article, Dr. Berwick states that the Affordable Care Act (Obamacare) will provide affordable care to all. $\mathrm{He}$ concludes that this new act will provide: "better care, better health and lower costs" [4]. The doctors have not supported this proposition and are working to have this act declared unconstitutional [5]. The creation and staffing of this incredible new government bureaucracy is well underway and is drawing fire from many fronts. We now have a move by the Obama administration to require a national patient ID card [6]. They have also asked HHS (Health and Human Services) to collect every citizens healthcare record in Washington for national processing and use [7]. The government continues to expand its rules and regulations by requiring Medicaid re-enrollment with the use of detailed demographics about each provider including a detailed background examination by an outside firm and fingerprints. 
I was personally asked to go through this process and this was the first time this has ever happened in my over 40 years of medical practice!

As a physician I was also required to complete a billing tutorial and examination this past year. In this online course, I was told that we now have at least seven independent groups auditing the medical records for fraud. Here is the list I was given: RAC-Recovery Audit Contractor; MICMedicaid Integrity Contractor; ZPIC- Zone Program Integrity Contractor; HEAT- Healthcare Fraud Prevention and Enforcement Action Team; MAC- Medicare Administration Contractor; CERT- Comprehensive Error Rate Testing; PERM- Payment Error Rate Testing. Each of these groups is rewarded for finding fraud and making doctors pay for mistakes in their billing. They claim that these groups recovered 2.5 billion dollars last year [8]. Any physician could be the target of these groups. Remember, they are in it for the money and if they don't find something they get no cash rewards. They are looking at billing upcoding, billing mistakes, lack of chart documentation, missing signatures and unnecessary services (who makes this decision?). There are both financial and legal consequences for these errors that could put a physician in jail for his staff or computer's errors. With an EMR doing a good share of the coding and filling in the documentation, it is possible to be attacked and destroyed by your own EMR!

Is it any wonder that physicians are not excited about their profession and its future. Soon it will be hard to find anyone willing to go into private practice. Patients will be left with the large groups and medical centers for their routine as well as specialty care. The solo practitioner is soon to become extinct and your healthcare system will look very much like Canada or England.

In the midst of this storm of healthcare regulations and "change", Dr Berwick departed his role as CMS Director. He was famous for his public support of care and service rationing, and the introduction of "death panels" [9]. In the new Obamacare world, these "death panel" are called IPABs (Independent Payment Advisory Board). These groups are still in the early stages of development. The members of the IPABs are unelected, unsupervised, unaccountable bureaucrats that will establish what will and will not get paid. These healthcare czars don't have to be physicians nor do the report to anybody. These are the rationing directors that control the payment system for all healthcare services in the US [10]. What the government does will be mimicked by the insurance carriers once this process begins.

This is not the only group or plan to watch. The Obama administration has published rules for hospitals to cut Medicare costs by forcing efficiency rules that reward spending less for Medicare patients. If the hospital fails to cut Medicare services on an average patient basis, it will be financially penalized [11]. This is a green light for hospitals to offer fewer services and care for the elderly to increase their government support. Wow, what a great idea and what a great reward for our seniors! We are also seeing states doing the same thing with panels of "experts" who decide who gets covered and who doesn't [12]. When the government takes on the role of healthcare policeman there will always be unintended consequences. Once the decision leaves the bedside, who knows what could happen to you in an emergency? This is where we are at with big government deciding who lives and who dies.

\section{Patient medical record security-2011}

With the use of computers in healthcare delivery comes the risk of information breaches and hacking. This year has seen a number of major losses. At UCLA patient's data was stolen from a doctor's home that included data on over 16,00 records [13]. Fairview Hospital and North Memorial Hospital in Minneapolis had records stolen from a contractor. Over 16,000 records were lost [14]. The grand-daddy of all breaches this year was the federal government. TRICARE, the military medical care system, lost 4.9 million medical records from a vendor's car. SAIC was the vendor and the government is being sued for $\$ 4.9$ billion dollars [15]. Stanford Hospital has had a major breach of medical records this year with the loss of 20,000 emergency room records. These records were posted online and the hospital is now being sued for this breach [16].

Each of these breaches of privacy are a signal that we may be moving in the wrong direction. The more you centralize and concentrate, the more likely this information will be stolen or hacked. A recent audit of HHS has shown that the agency is not policing the privacy requirements of hospitals and is not doing anything to oversee this process. The audit questions the intent of HHS to protect patient data [17]. This goes along with the constant discussion from informatics professionals that HIPAA is really irrelevant and an impediment to data mining for the future. Even the inspector general of HHS has publicly stated that HHS is overlooking security problems with all this push to computerize the medical records of all patients $[18,19]$.

There is also a sincere danger to making these large commitments to EMRs that can seriously damage a hospital and healthcare system. Gwinnett Medical Center in Lawrenceville and Duluth Georgia were recently hit by a computer worm that managed to shut down their entire system and campus for 3 days [20]. We have had other reports of similar system failures in Florida and each of these has stressed the entire staff to maintain stability when the computer fails to deliver services. There was always a requirement in old system design plans to have a solid paper backup plan in place and to practice it often. I am afraid we have gone long 
past that goalpost and are now operating on a $100 \%$ uptime requirement. We must hope that this $100 \%$ assumption is never seriously tested.

\section{Informatics business-2011}

While the medical IT revolution is being fueled by federal funds at an astonishing rate, hospitals and clinics are still struggling to cope with this massive overhaul. Hundreds of millions of dollars are flowing into contractors to help install and maintain these systems. Epic seems to be the biggest winner and their installers are making a killing in the job market with all the new installations on the horizon.

In a surprise announcement, IBM has said that the Obama administration will not accept their offer to reduce Medicare fraud for free [21]. It seems that the IBM offer included a free program to save one trillion dollars in fraud and the President said: "No thanks". Wow. Something is definitely wrong in Washington and it is obvious that common sense has left town. IBM has also moved their Watson project into the healthcare arena with a joint venture to assist Wellpoint find the right answers to their medical Jeopardy questions [22, 23].

As we look east across the Atlantic to that shining healthcare system in England (the NHS) which Dr. Berwick loves, we find that they are shutting down their IT operation which they say has been moribund for months [24, 25]. This multibillion pound system has been under development for over 10 years and has now come to a stage where they are considering starting over. The chairman of the committee overseeing this project said: "Trying to create a one-sizefits-all system in the NHS was a massive risk and has proven to be unworkable [26]." Is that our fate with a central command center in Washington driving all the specifications? With all our money and resources being spent on connectivity, where is the money to modify and perfect what already exists? There are no corporate funds to improvise and innovate [27]. The government keeps changing the bar and the companies have to follow or they will be seen as non-compliant. Will this centralized control and manipulation lead to a system that eventually looks like the NHS? Time and your money will soon tell.

In 2008, Google made a huge announcement and entered the electronic medical record market. They were going to be the central source for personal health records. They pledged their corporate might, money and expertise to make this happen. Well, after 3 years they have sounded a retreat and Google health is dead. You have one year to get your records off their system. All records will disappear after 2013 [28].

On a positive note, Apple seems to be the winner in 2011. They have managed to introduce a product that has the right touch and feel for medicine-the iPad. Clear Practice has built their cloud based system on this platform and now has their
AP on the Apple website. There are a host of other medical APs that you can select from the Apple library. We are seeing a major seismic change in physician behavior with the introduction of this device. Even medical schools such as Yale are shifting their teaching platform to this tool [29]. It is now common to see doctors on rounds with these devices and their hospital EMRs are rapidly adapting to this technology with APs for their use [30, 31].

\section{Summary}

2011 has been a productive year for may hospitals that have gone through the conversion process to a fully integrated EMR. This is expensive and traumatic for the entire staff. We must now throttle back on the accelerator and let these systems settle and mature so that the bugs and problems can be resolved. England made serious mistakes in the pressure they placed on a central control of everything and it has cost them their investment. We need to learn from their experience and let innovation and experimentation be done on what is presently in the field so that we do not force inefficiency and error on those who follow. The companies need to spend less on connectivity and more on system improvement and physician modifications. Less regulatory control and more quality control are needed. Are these new systems really working and are they going to keep working? These questions need answers before more money is spent and perhaps wasted. Without the support of the staff and medical community, this whole investment will be wasted and the effort will be less than optimal. Let's hope sanity returns to Washington this year and we have an opportunity to study and analyze our current progress.

\section{References}

1. Olasky, S., Under the Weather. World Magazine, May 7, 2011.

2. Brown, J., Physicians Charging Annual Fees? Stop the Presses!. physiciansmoneydigest.com, May 13, 2011.

3. Kavilanz, P., Doctor's Going Broke. CNNMoney.com, January 5, 2012.

4. Berwick, D., We can have it all. Modernhealthcare.com, May 17, 2011.

5. Association of American Physicians and Surgeons, December 7, 2011.

6. CCHF News and Alerts, "Comments on proposed National Patient ID Card", September 2, 2011.

7. Huelskamp, T., Obamacare HHS rule would give government everybody's health records. Washingtonexaminer.com, September 23, 2011.

8. University of Florida Billing Compliance Certification Program PBC800, May 18, 2011.

9. Wolf, M., Berwick leaves town. wasingtontimes.com, December 1, 2011.

10. Kurtz, S., The Acronym that Ate Health Care. National Review, May 16, 2011. 
11. McCaughey, B., New Medicare Efficiency measure Deadly to Seniors. newsmax.com, June 3, 2011.

12. A Panel Decides Washington State's Health Care Costs. New York Times, March 22, 2011.

13. Gorman, A., UCLA Medical Official says Patient Information data Stolen. LA Times, November 5, 2011.

14. Goedert, J., Contractor Breach Hits two Health Systems. healthdatamanagement.com, September 28, 2011.

15. Goedert, J., TRICARE Hit with $\$ 4.9$ Billion Suit Following Breach. healthcaredatamangement.com, October 17, 2011.

16. Sack, K., Patient Data Posted Online in Major Breach of Privacy. New York Times, September 8, 2011

17. Conn, J., Audit Reports hit HHS on Digital Security. modernhealthcare.com, May 17, 2011.

18. Associate Press, HHS inspector general says push for electronic medical records overlooks some security gaps. washingtonpost. com. May 17, 2011.

19. Simmons, J., ONC isn't protecting patient data, OIG finds. fiercehealthit.com, May 18, 2011.

20. Liebowitz, M., Computer worm forces hospitals to turn away patients. securitynewsdaily.com, December 14, 2011.
21. Wall Street Journal, October 5, 2011.

22. Associated press, IBM Supercomputer Watson to Help Diagnose medical Problems. foxnews.com, September 12, 2011.

23. Anderson, C., Wellpoint to help IBM bring Watson technology to market. healthcareitnews.com, September $12 \mathrm{~m} 2011$.

24. UK News, UK NHS IT Project Shutdown. September 23, 2011.

25. Ball, J., NHS budget squeeze to blame for longer waiting times, say doctors. guardia.co.uk, May 19, 2011.

26. Triggle, N., Pull plug on NHS e-records -MPs. BBC News, August 2, 2011.

27. Goedert, J., OptumInsight CEO: Meaningful Use Helps EHR Adoption, Hampers Innovation. healthcaredatamanagement.com, June 2, 2011.

28. Wall Street Journal, Google health, R.I.P. June 24, 2011.

29. Mercola.com, 14 Awesome Apps for your new smart phone or tablet that you should love. January 11, 2012.

30. Schramm, M., iPads used for diagnosis and treatment in Texas hospital. tuaw.com, June 6, 2011.

31. 12 ways iPads are changing hospital marketing and PR. Healthcaresuccess.com, August 10, 2011. 